\title{
LEGADO TEOLÓGICO DEL PADRE ALBERTO RAMÍREZ EN LA REVISTA CUESTIONES TEOLÓGICAS
}

\section{Theological Legacy of Father Alberto Ramirez in the Journal Cuestiones Teológicas Legado teológico do Padre Alberto Ramírez na revista cuestiones teológicas}

\author{
Carlos Alberto Vargas González* \\ JuAN RicARdo GonZÁLEZ Lopera** \\ Felipe Agudelo Olarte***
}

\begin{abstract}
"Es cierto que podemos esforzarnos por encontrar la racionalidad de nuestra fe en Dios, pero más que eso debemos preocuparnos por dar razón total de un Dios, a quien podemos experimentar con toda la capacidad de experimentación existencial que tenemos" Padre Alberto Ramírez.
\end{abstract}

* Magíster en Administración de la Universidad Pontificia Bolivariana, Medellín. Teólogo de la misma universidad. Contador Público de la Universidad de Medellín, Colombia. Correo electrónico: carlosalberto.vargas@upb.edu.co

** Teólogo de la Universidad Pontificia Bolivariana, Medellín, Colombia.

Correo electrónico: juanricardogonzalezlopera@hotmail.com

*** Estudiante de octavo semestre de Teología de la Universidad Pontificia Bolivariana, Medellín, Colombia.

Correo electrónico: agudelofelipe2002@hotmail.com

Artículo recibido el 15 noviembre de 2016 y aprobado para su publicación el 10 diciembre de 2016. 


\title{
Resumen
}

A propósito de la publicación del número cien de la revista Cuestiones Teológicas de la Facultad de Teología de la Universidad Pontificia Bolivariana, este artículo tiene como objetivo mostrar los ejes transversales del pensamiento teológico del padre Alberto Ramírez Zuluaga, uno de los fundadores, tanto de la facultad como de la revista. Utilizando la metodología de revisión sistemática de literatura, se rastrearon los artículos publicados por él en este medio. Como resultado se encontró que los tratados teológicos más recurrentes son: teología fundamental, eclesiología y sacramentología.

\section{Palabras clave}

Alberto Ramírez Zuluaga, Revista Cuestiones Teológicas, Perfil intelectual, Teología.

\begin{abstract}
In commemoration of the 100th issue of the journal Cuestiones Teológicas, a publication of the department of Theology at Universidad Pontificia Bolivariana, the article seeks to present the main themes of father Alberto Ramírez Zuluaga's theological thought, one of the founders of both the department and the journal. Employing systematic review methods, his published articles and papers in this journal were collected and analyzed. Thus, it was found that he mainly worked on the following theological topics: Fundamental Theology, Ecclesiology, and Sacramentology.
\end{abstract}

\section{Key words}

Alberto Ramírez Zuluaga, Cuestiones Teológicas, Intellectual Profile, Theology.

\section{Resumo}

A propósito da publicação do número cem da revista Cuestiones Teológicas da Faculdade de Teologia da Universidad Pontificia Bolivariana, este artigo tem o objeto de mostrar os eixos transversais do pensamento teológico do Padre Alberto 
Ramírez Zuluaga, um dos fundadores, tanto da faculdade como da revista. Utilizando a metodologia de revisão sistemática da literatura, foram rastreados os artigos por ele publicados neste meio. Como resultado se encontrou que os tratados teológicos mais recorrentes são: teologia fundamental, eclesiologia e sacramentologia.

\section{Palavras-chave}

Alberto Ramírez Zuluaga, Revista Cuestiones Teológicas, Perfil intelectual, Teologia.

\section{INTRODUCCIÓN}

Un legado desde la perspectiva del pensamiento teológico de un hombre, el padre Alberto Ramírez Zuluaga, en cuya teología se evidencia una continua profesión de fe y un servicio ministerial de su ser sacerdotal, tiene un alcance más allá de lo que las categorías pueden dar cuenta. De allí que los autores de este artículo, todos afortunados de haber asistido a los cursos dictados por el teólogo mencionado y de haber tenido el privilegio de investigar junto con él, quieren ofrecer en homenaje y con ocasión de la publicación del número cien de la revista Cuestiones Teológicas, un esbozo acerca del pensamiento teológico del padre Alberto Ramírez Zuluaga en la revista mencionada, dejando constancia de su legado para la revista misma, para la Facultad de Teología de la Universidad Pontificia Bolivariana, para la Arquidiócesis de Medellín y para el pensamiento teológico en general.

Esta investigación es fruto de una revisión sistemática de literatura ${ }^{1}$ de los artículos publicados por el padre Alberto Ramírez Zuluaga en la revista Cuestiones Teológicas, donde se tiene por objetivo mostrar los ejes transversales de su pensamiento, los cuales se convierten en un punto de partida para posteriores investigaciones acerca de su pensamiento teológico.

1 En adelante, cada vez que se haga referencia al método Revisión Sistemática de Literatura, se utilizará la abreviatura RSL. 
En ese sentido, este artículo, por un lado, dará cuenta de la metodología con la cual se procedió para hacer la RSL; y, por otro, hará un análisis de los resultados, desde lo cuantitativo y lo cualitativo, poniendo de manifiesto los temas teológicos recurrentes del Padre Alberto Ramírez Zuluaga.

\section{METODOLOGÍA}

En la presente RSL se busca dar respuesta a la siguiente pregunta: ¿cuáles son las temáticas recurrentes en los artículos publicados por el padre Alberto Ramírez Zuluaga en la revista Cuestiones Teológicas entre 1974 y 2015? En este trabajo se han excluido los demás artículos y publicaciones del autor, al igual que las reseñas bibliográficas que aparecen dentro de la revista en mención.

El plan de búsqueda llevado a cabo en esta RSL ha sido el acceso a las fuentes físicas del archivo de la Facultad de Teología, donde se encuentra la colección completa de la revista Cuestiones Teológicas. Luego se realizó un catálogo de todos los artículos cuya autoría fueran del padre Alberto Ramírez y fueron clasificados en los diferentes tratados de la teología a los que hacían referencia. Posteriormente se identificaron cuáles eran las temáticas que poseían un mayor número de artículos, a la vez que los subtemas recurrentes en cada una de ellas.

\section{ANÁLISIS DE LOS RESULTADOS}

\section{Análisis cuantitativo}

La RSL, según el alcance determinado, llevó a evidenciar, en términos cuantitativos, 60 artículos escritos por Alberto Ramírez Zuluaga, dentro de los cuales se encontró mayor frecuencia en estos ámbitos del pensamiento teológico: teología fundamental, eclesiología y sacramentología. La siguiente gráfica da cuenta de la recurrencia cuantitativa, en número de artículos, de los tópicos mencionados: 


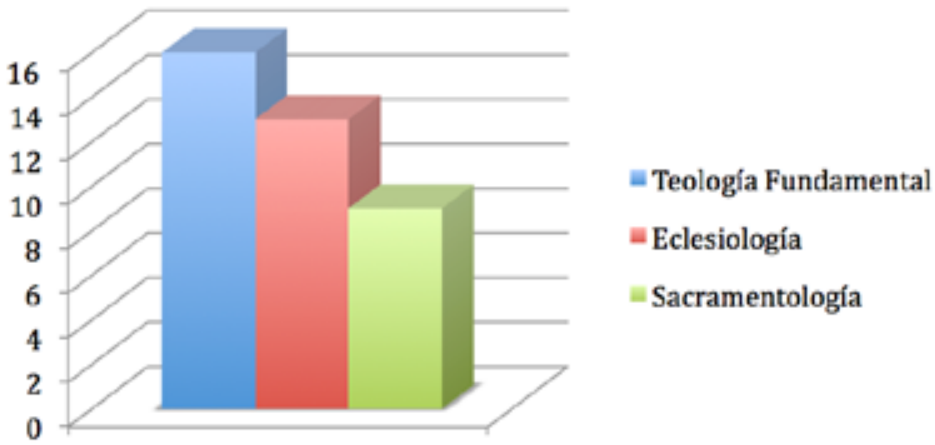

Número de artículos

A continuación se hará referencia a cada uno de los temas anteriormente enunciados mostrando, a través de cuadros, el año de la publicación, el volumen, el número, el título y las páginas en las cuales se encuentran los diferentes artículos dentro de la revista Cuestiones Teológicas.

\section{Teología fundamental}

En la RSL se encontraron 16 artículos respecto a la teología fundamental, que tienen como tópicos más recurrentes la relación fe y razón, la teología como ministerio eclesial, la teología en situación y en diálogo con la cultura. El siguiente cuadro da cuenta detallada de los artículos:

\begin{tabular}{|c|c|c|c|c|}
\hline Año & Volumen & Número & Título & Páginas \\
\hline \multirow[t]{2}{*}{1974} & 1 & 1 & $\begin{array}{l}\text { El problema de la historia a la luz de la } \\
\text { teología }\end{array}$ & $75-81$ \\
\hline & & & Escritura - Teología - Iglesia & $82-95$ \\
\hline 1976 & 3 & 6 & La revelación de Dios y su transmisión & $15-34$ \\
\hline 1984 & 11 & 29 & $\begin{array}{l}\text { Las categorías antropológicas y los } \\
\text { existenciales cristianos en la teología }\end{array}$ & $5-17$ \\
\hline \multirow[t]{2}{*}{1986} & 13 & 35 & Qué es hacer teología & $73-80$ \\
\hline & & 36 & $\begin{array}{l}\text { Diálogo fe-cultura en el contexto } \\
\text { universitario }\end{array}$ & $27-35$ \\
\hline \multirow[t]{2}{*}{1987} & 14 & 37 & ¿Es posible un modelo teológico nuevo? & $81-104$ \\
\hline & & 39 & $\begin{array}{l}\text { La dimensión hermenéutica de la fe y el } \\
\text { proyecto hermenéutico en teología }\end{array}$ & $39-45$ \\
\hline
\end{tabular}




\begin{tabular}{|c|c|c|c|c|}
\hline Año & Volumen & Número & Título & Páginas \\
\hline 1998 & 24 & 64 & $\begin{array}{l}\text { ¿Hacia dónde va la religión? Aproximación } \\
\text { al discurso filosófico-teológico de José } \\
\text { María Mardones en torno a la relación } \\
\text { post-modernidad y religión }\end{array}$ & $71-87$ \\
\hline 2000 & 27 & 67 & $\begin{array}{l}\text { Consideraciones teológicas acerca del } \\
\text { misterio de Dios }\end{array}$ & $81-115$ \\
\hline \multirow[t]{2}{*}{2001} & 28,1 & 69 & $\begin{array}{l}\text { La globalizacion y el futuro de la religión } \\
\text { en el mundo }\end{array}$ & $59-67$ \\
\hline & 28,2 & 70 & $\begin{array}{l}\text { Esperar a pesar de todo. Reflexiones } \\
\text { sobre el consuelo apocalíptico con } \\
\text { ocasión de los atentados terroristas del } \\
11 \text { de septiembre en Estados Unidos y } \\
\text { de la guerra mundial declarada contra el } \\
\text { terrorismo }\end{array}$ & $135-146$ \\
\hline 2005 & 32 & 78 & Palabra de Dios y sanación de la memoria & $225-241$ \\
\hline 2008 & 35 & 84 & $\begin{array}{l}\text { La conferencia de Medellín y la teología } \\
\text { de la esperanza }\end{array}$ & $235-254$ \\
\hline 2012 & 39 & 92 & $\begin{array}{l}\text { La Palabra y el silencio. Categorías } \\
\text { antropológicas para desentrañar el } \\
\text { fenómeno de la revelación y la fe }\end{array}$ & $\begin{array}{l}197 \\
213\end{array}$ \\
\hline 2015 & 42 & 97 & $\begin{array}{l}\text { Fenomenología y teología de la liberación: } \\
\text { el giro teológico en la teología de América } \\
\text { Latina }\end{array}$ & $229-249$ \\
\hline
\end{tabular}

\section{Eclesiología}

En lo relacionado con este aspecto, en la RSL se hallaron 13 artículos que hacían alusión al tratado eclesiológico. Como tópicos más recurrentes se encontraron la eclesiología del Concilio Vaticano II y de la Conferencia de Medellín, la ministerialidad y el laicado. El siguiente cuadro muestra detalladamente los artículos:

\begin{tabular}{ccclc}
\hline Año & Volumen & Número & \multicolumn{1}{c}{ Título } & Páginas \\
\hline 1974 & 1 & 1 & $\begin{array}{l}\text { Escritura - Teología - Iglesia } \\
\text { Síntesis sistemática sobre la propia }\end{array}$ & $82-95$ \\
1975 & 2 & 5 & $\begin{array}{l}\text { identidad de los ministerios y carismas 3-28 } \\
\text { en la Iglesia }\end{array}$
\end{tabular}




\begin{tabular}{|c|c|c|c|c|}
\hline Año & Volumen & Número & Título & Páginas \\
\hline 1978 & 5 & 11 & La Iglesia como comunidad ministerial & $38-51$ \\
\hline 1980 & 7 & 19 & 450 años desde la confessio augustana & $59-70$ \\
\hline 1983 & 10 & 26 & $\begin{array}{l}\text { Fundamentos doctrinales para una } \\
\text { teología sobre la acción del laico }\end{array}$ & $24-35$ \\
\hline 1985 & 12 & 32 & $\begin{array}{l}\text { A los } 20 \text { años de la clausura del } \\
\text { concilio ecuménico Vaticano II }\end{array}$ & $100-106$ \\
\hline 1987 & 14 & 39 & $\begin{array}{l}\text { La teología del laicado desde el } \\
\text { concilio Vaticano II hasta el sínodo } \\
\text { mundial actual }\end{array}$ & $49-64$ \\
\hline 1995 & 21 & 57 & $\begin{array}{l}\text { Fe y tolerancia. Reflexiones acerca de } \\
\text { la apertura religiosa en vísperas del } \\
\text { advenimiento del tercer milenio }\end{array}$ & $79-102$ \\
\hline 1997 & 23 & $\begin{array}{l}61- \\
\text { Selección } \\
\text { No. } 1\end{array}$ & $\begin{array}{l}\text { Una oferta revolucionaria sobre el } \\
\text { ministerio del primado en el diálogo } \\
\text { ecuménico }\end{array}$ & $45-48$ \\
\hline 1998 & 24 & 63 & $\begin{array}{l}\text { "Medellín” y el origen reciente de la } \\
\text { vocación profética de nuestra Iglesia } \\
\text { en América Latina }\end{array}$ & $21-44$ \\
\hline 1999 & 26 & 66 & $\begin{array}{l}\text { El reto actual de la apertura toca } \\
\text { también a la Iglesia y a la teología: } \\
\text { Consideraciones en torno al futuro de } \\
\text { la vocación profética de la Iglesia y de } \\
\text { la teología en América Latina }\end{array}$ & $123-144$ \\
\hline 2003 & 30 & 73 & $\begin{array}{l}\text { A los } 40 \text { años de la inauguración del } \\
\text { Concilio Vaticano II }\end{array}$ & $29-55$ \\
\hline 2010 & 37 & 88 & $\begin{array}{l}\text { El futuro de la Iglesia. La misión como } \\
\text { proyecto de llevar el Evangelio hasta el } \\
\text { corazón de la cultura y de las culturas }\end{array}$ & $335-368$ \\
\hline
\end{tabular}

\section{Sacramentología}

Por último, en la RSL se hallaron 9 artículos que hacían referencia a la teología de los sacramentos. Como tópicos recurrentes en este punto se hallan: el misterio Pascual, los sacramentos en general y de manera particular el Sacramento de la Eucaristía. En el siguiente cuadro se muestra la relación de los artículos: 


\begin{tabular}{|c|c|c|c|c|}
\hline Año & Volumen & Número & Título & Páginas \\
\hline 1975 & 2 & 5 & $\begin{array}{l}\text { Síntesis sistemática sobre la propia } \\
\text { identidad de los ministerios y } \\
\text { carismas en la Iglesia }\end{array}$ & $3-28$ \\
\hline \multirow{2}{*}{1977} & \multirow{2}{*}{4} & \multirow{2}{*}{ Extraordinario } & Eucaristia y sacerdocio & $62-77$ \\
\hline & & & El diaconado permanente & $90-97$ \\
\hline \multirow{2}{*}{1978} & \multirow{2}{*}{5} & 11 & $\begin{array}{l}\text { La Iglesia como comunidad } \\
\text { ministerial }\end{array}$ & $38-51$ \\
\hline & & 12 & $\begin{array}{l}\text { La eucaristía sacramento sacrificial } \\
\text { de la Iglesia }\end{array}$ & $43-55$ \\
\hline 1981 & 8 & 22 & $\begin{array}{l}\text { Algunos principios doctrinales para } \\
\text { una reflexión sobre la iniciación } \\
\text { cristiana }\end{array}$ & $\begin{array}{l}131- \\
137\end{array}$ \\
\hline 1982 & 9 & 24 & $\begin{array}{l}\text { El encuentro sacramental de la } \\
\text { salvación }\end{array}$ & $88-104$ \\
\hline 1983 & 10 & 27 & Apuntes sobre los sacramentos & $23-56$ \\
\hline 2003 & 30 & 74 & $\begin{array}{l}\text { La Memoria del Señor: Fuentes de } \\
\text { la celebración pascual de la Iglesia } \\
\text { e interrogantes que se plantean a } \\
\text { partir de dichas fuentes }\end{array}$ & $\begin{array}{l}331 \\
357\end{array}$ \\
\hline
\end{tabular}

\section{Análisis cualitativo}

En esta parte se pretende hacer énfasis en las temáticas frecuentes encontradas en el análisis cuantitativo; es decir, se estudiará individualmente el pensamiento de Alberto Ramírez con respecto a la teología fundamental, eclesiología y sacramentología.

\section{Teología fundamental}

Uno de los temas frecuentes en la reflexión de Alberto Ramírez es la teología fundamental desde sus diferentes ámbitos, tales como la relación de la fe y la razón, la identidad, el sujeto, el método y el objeto de la teología y la teología en situación y en diálogo con la cultura. Todo esto inspirado, sin lugar a dudas, en el imperativo de la Primera carta de Pedro 3,15: "estén siempre dispuestos a dar razón de su esperanza”.

Estudiar el objeto, el método, el sujeto, las fuentes y los lugares de la teología era uno de sus temas de investigación; esta RSL da cuenta de 
ello, pues es usual en el autor una continua referencia a la teología desde los tópicos mencionados (Ramírez, 1974a; 1974b; 1976; 1986a; 1986b; 1987; 2000; 2012).

\section{La teología como proceso del logos en su totalidad.}

Un aspecto relevante en su teología es aquel según el cual la teología no puede caer en la frialdad del racionalismo, ni tampoco alejarse de aquellas razones que van más allá de la argumentación lógica y dan paso, incluso, al lenguaje del sentimiento. $\mathrm{Al}$ respecto, un texto profundo del autor ilustra magistralmente así:

Dios se deja pensar [...] Se puede hablar racionalmente sobre Dios. Sin embargo, Dios también se deja sońar. Desde este punto de vista, la teología no es solo la búsqueda de una racionalidad parcial de la fe, sino la búsqueda de una racionalidad integral de la misma, que también podríamos llamar existencial. Dios no existe solamente para nuestra razón: también existe para nuestro (nuestra) 'co-razón' (2000, p. 83).

La teología, por tanto, ha de considerar la totalidad de lo que se entiende por logos y no reducirse simplemente a la connotación racional del mismo. Hacer teo-logía es acercarse a Dios a través de todas las dimensiones del logos y no solamente por medio de la manera técnica de entender la razón, la cual es reducida a la dimensión cognoscitiva del hombre y conduce a unos fines concretos.

Por eso, es preciso recordar el sentido ontológico de dicha categoría; no tener presente sólo la dimensión cognoscitiva-utilitarista del ser humano al momento de hacer teo-logía, sino también la estética, la práctica, la apasionada, la subjetiva y la objetiva. Así, para el padre Alberto la verdadera teología comprende al hombre en su totalidad. Se puede colegir que según su pensamiento, a la teología nada de lo humano le puede ser indiferente para ser tal, puesto que el camino de la teología es el hombre.

\section{La teología como ministerio eclesial.}

Por otro lado, se evidencia cómo para él la teología cumple un ministerio diaconal en cuanto que es un servicio eclesial. Este ministerio no puede 
supeditarse únicamente a repetir la palabra magisterial de la Iglesia, ni mucho menos pensarse que este le corresponde exclusivamente al ministerio jerárquico. Argumentando en este sentido, el padre Alberto (1976) asevera lo siguiente: "Lamentablemente no es bien clara la ubicación actual de este ministerio eclesial. Con frecuencia puede él aparecer como un ministerio de competencia con el ministerio jerárquico, el que también a veces es simplemente comprendido como ministerio teológico indebidamente" (p. 33).

En efecto, según él (1986a), este ministerio ha de comprenderse al interior de la comunidad cristiana y al servicio de la misma, lo que no significa necesariamente que la teología sea exclusivamente otro mecanismo más de transmisión de lo que dice la Iglesia en términos oficiales. No obstante, una teología "extra ecclesiam" tampoco puede ser considerada teología católica. Una prueba de ello se evidencia en su propia reflexión, en la que tenía como una de sus principales fuentes el magisterio eclesial; basta leerlo para encontrar continuas referencias a los concilios, las conferencias episcopales y los diferentes documentos y enseñanzas de los Papas.

Alberto Ramírez es un testimonio de que el teólogo profesional se crea y se re-crea al interior y al servicio de la Iglesia. Él vivió su bautismo y su sacerdocio radicalmente a través del ministerio diaconal de la teología.

\section{Teologia "in situ"}

Otro aspecto importante es que la teología tiene que hacerse en situación, lo cual no significa que deba desconocerse la Tradición, al contrario, debe alimentarse de esta para interpretar el hoy de la historia y volcarse hacia el futuro. Una teología cuyo camino no sea el hombre en la totalidad de sus circunstancias carece de asidero en la actualidad. De allí que la teología sea una continua traducción de lo ya elaborado previamente por las investigaciones positivas y por el magisterio eclesial, para expresarlo así en un lenguaje capaz de llegar al corazón del hombre, en su realidad concreta (1976).

De su pensamiento puede colegirse que una teología incapaz de hacerse en situación y de ser una traducción para el hombre, puede correr el riesgo de quedarse en el rincón de un círculo de peritos que no cumple con la condición fundamental de dar razón de la esperanza. 
Otro riesgo que apunta es: "[...] la teología no puede tener una función puramente reproductora. No es la pura repetición de lo establecido, aun dogmáticamente" (1987, p. 44). Este quehacer no puede olvidar su función creativa y debe saber que la dimensión del tiempo le pertenece predilectamente es el futuro: "[...] ella debe abrir siempre los nuevos horizontes que pertenecen necesariamente a la revelación" (1976, p. 33), teniendo como base "[...] las raíces mismas de la fe para recorrer un largo camino que debe llevar siempre más allá de la meta que han alcanzado nuestros antepasados" (1987, p. 44).

Estas declaraciones del padre Alberto Ramírez son necesarias para evitar varios extremos que suelen darse en el quehacer de la teología misma. Por un lado están los mal llamados "conservadores" que basan sólo su pensamiento teológico en lo que ya se ha dicho y dedican todos sus esfuerzos a reestablecer casi como absoluto algo que surgió en un contexto que no es el del hombre actual. Por otro lado, existe un grupo de "vanguardistas" o "progresistas" que quiere desconocer todo la herencia reflexiva que tiene la Iglesia y la teología. En este sentido, el legado del padre Alberto permite comprender que la teología bebe del pasado para abrir una nueva posibilidad en el abanico del futuro de la reflexión de la fe.

\section{Eclesiología}

La eclesiología del padre Alberto Ramírez adquiere, tanto en su persona como en su exposición, un carácter testimonial dada la vivencia que él tuvo de los acontecimientos que, a nivel universal y latinoamericano, en los últimos cincuenta años fueron decisivos en la renovación y fundamentación del tratado sobre la Iglesia. En esta RSL se esbozarán brevemente cuatro aspectos al respecto.

\section{El Concilio Vaticano II.}

La referencia del Concilio ha sido transmitida por el padre Alberto como experiencia y testimonio. Se refiere a él como "un verdadero don de Dios"; y al momento en que se vivió y al tiempo posterior los describe como una "época providencial" (1985, p. 102). Esto permite percibir la visión de fe con que el padre Alberto se acercaba a este tema-acontecimiento, al que no percibía como un simple hecho coyuntural. 
Su referencia al Concilio está siempre unida al recuerdo de sus maestros de Lovaina, especialmente Mons. Gérard Philips, quien lo marcó profundamente, no sólo por su persona y densidad teológica, sino por ser su profesor de eclesiología al tiempo que se dedicaba a la redacción del esquema de la que sería posteriormente la Constitución Lumen Gentium.

Igualmente el padre Alberto (1985) comparte la posición de Karl Rahner, quien fuera uno de los teólogos principales del Vaticano II, para quien el Concilio es punto de partida y no una barrera que impide el posterior desarrollo de la Iglesia, contrario a la posición de quienes querían limitar el desarrollo del Concilio a lo que estrictamente se habló en él. La visión de horizonte propia del Concilio la da a conocer al explicar que: "[...] un Concilio no consiste simplemente en documentos que se conocen sobre los cuales se adquiere información, sino en el impulso, que no es otra cosa que la fuerza misma del Espíritu, para vivir con orientación de futuro" (1985, p. 106).

En este punto es interesante resaltar su propuesta sobre el Concilio como un "mínimum" (Ramírez, 1978), es decir, no como la palabra definitiva y última sobre diversos temas, sino como palabra mínima y orientadora que aporta el punto de comunión necesario y en el cual se debe estar de acuerdo para la construcción de la Iglesia. Esto permite nombrar a la teología del padre Alberto en general como una teología verdaderamente conciliar. Su punto de partida serán siempre las pautas dadas por el Concilio para continuar abriendo camino. Su teología es, por tanto, una teología de futuro, de la esperanza.

Entre las características de la eclesiología conciliar se encuentra el paso de una eclesiología vertical a la del diálogo, entendida como actitud de apertura para todas las instituciones y que, a partir del Concilio, "se ha convertido en actitud ideal humana, cristiana y eclesial" (Ramírez, 1985, p. 105). Así mismo, analizando la alocución Gaudet Mater Ecclesia en la apertura del Vaticano II por el Papa Juan XXIII el 11 de Octubre de 1962, el padre Alberto habla de tres objetivos que desde el inicio le fueron fijados al Concilio y que según él, pueden reconocerse a posteriori (2003, p. 36): 1) La renovación (aggiornamento) de la Iglesia por el retorno a las fuentes; 2 ) el diálogo, entendido como la manera auténticamente cristiana y evangélica de realizar la relación entre las personas, entre las comunidades, en todas 
las instancias de la humanidad; 3) el objetivo pastoral del Concilio que se expresó en la Gaudium et Spes.

Finalmente, es interesante reconocer que el padre Alberto establece una estrecha relación entre el Concilio y la Arquidiócesis de Medellín con sus esfuerzos de renovación entre los cuales destaca la facultad de teología con una "firme inspiración conciliar" (1985, p. 103).

\section{La eclesiología en América Latina a partir de la Conferencia de Medellín.}

La experiencia de la Conferencia de Medellín también fue vivida de cerca por el padre Alberto tras su regreso de los años de estudios en Alemania y Bélgica. Según él, esta Conferencia del CELAM es: "un punto de referencia eclesial y pastoral de tal manera necesario, que sin él no encontramos fácilmente la memoria original constituyente de lo que somos, pensamos y vivimos como Iglesia, en nuestro mundo concreto latinoamericano" (1998, p. 24). Por esto, "Medellín" no solo es importante respecto al tratado eclesiológico, sino también frente a la identidad de la Iglesia latinoamericana.

En el desarrollo de esta temática se resalta el papel de "Medellín” como punto de recepción original del Concilio en América Latina, permitiendo que esta Iglesia se interrogara acerca de su autenticidad evangélica y del sentido histórico de su misión pastoral. Más específicamente, según Alberto Ramírez (1998), la Conferencia de Medellín, inspirada por el Concilio, sirvió para que la Iglesia de esta parte del continente tomara la decisión de ser una Iglesia renovada según el Evangelio, para asumir con entusiasmo la misión pastoral como una diaconía en la historia del mundo latinoamericano desde los siguientes aspectos:

a. En el plano de su propia conciencia eclesial se da: la recuperación del concepto de pueblo de Dios como sujeto total de la comunidad; el esfuerzo de renovación en el sentido de la apertura y del diálogo tanto al interior de la misma Iglesia como hacia afuera; y el redescubrimiento, en el espíritu de la pobreza evangélica, del rostro del Señor.

b. En opciones pastorales, teniendo en cuenta el reto de las circunstancias históricas de aquel momento, se quiere hacer surgir una Iglesia con carisma profético, es decir: "[...] una Iglesia que acompaña profundamente la vida de los hombres, su historia, con los ideales del 
Reino de los cielos: así se ha soñado la Iglesia de América Latina desde "Medellín”' (1998, p. 40).

En su exposición sobre este acontecimiento decisivo de la Iglesia de América Latina, el padre Alberto resalta el carácter de independencia y personalidad eclesial autónoma que adquirió esta porción de la Iglesia en "Medellín", a partir de la cual, "[...] empezamos a ser una Iglesia que no se contenta simplemente con recibirlo todo de la Iglesia universal, sino que tiene una gran riqueza para aportar a la misma, para hacer crecer en ella la autenticidad evangélica” (1998, p. 44).

Así como con el Concilio, el padre Alberto vuelve sobre "Medellín" siempre al suceso más que al texto, dado que este es incomprensible sin la visión del acontecimiento: "No es la letra de los Documentos sino el espíritu de los acontecimientos lo que es verdaderamente importante" (1998, p. 41). Su eclesiología es, por tanto, la del actuar del Espíritu en la Iglesia, cuya huella es perceptible en los acontecimientos que siguen siendo hasta hoy memoria y actualidad.

\section{La ministerialidad en la Iglesia}

El tema de la ministerialidad, al igual que el de los carismas, es abordado por el padre Alberto siempre en el contexto de la Iglesia. Según él, ellos no pueden ser comprendidos como una entidad aparte, dado que la jerarquía no es identificable con la totalidad de la Iglesia, sino que esta se refiere a la totalidad del pueblo cristiano; y porque los ministerios "no constituyen un fenómeno extraeclesial, o mejor supraeclesial, sino una dimensión constitutiva de la Iglesia" (1975, p. 6).

Su eclesiología mantiene, fiel al espíritu conciliar, la primacía de la comunión, definiendo a la Iglesia como una comunión de hombres que en el Espíritu Santo caminan por Jesucristo hacia el Padre. Por esto, la ministerialidad es auténtica en cuanto brota de la comunión y la posibilita. Así, presenta como función propia de los ministerios la presidencia de la comunidad en sus diferentes ámbitos: la evangelización, el sacerdocio y el régimen pastoral.

Otro elemento propio de los ministerios es su carácter de servicio. La ministerialidad en la teología del padre Alberto, como en el Concilio, es 
comprendida en términos de diaconía a los hombres en todos los ámbitos de su existencia, dejando atrás la distinción entre lo sagrado y lo profano; sin embargo, según él: "[...] esta ambigüedad no está todavía superada totalmente en la eclesiología conciliar” (1975, p. 27). ¿Para qué están entonces los ministerios en la Iglesia? A partir de la eclesiología del padre Alberto, se puede responder: para la construcción de la comunidad y para hacer posible la realización de la misma.

\section{El Laicado}

Al hablar del laicado, el padre Alberto recuerda que, a partir del Concilio, toda la comunidad es sujeto activo de la realización de la misión del cristiano y ya no únicamente los clérigos o religiosos. Según afirma: "[...] el laicado es simplemente la condición cristiana. Ser laicos significa ser cristianos, ser miembros del pueblo de Dios, ser bautizados, ser la Iglesia" (1983, p. 28).

Al desarrollar este tema, el padre Alberto expone las ideas fundamentales sobre el laicado en la eclesiología conciliar:

a. La personalidad eclesial del laicado: es sujeto y miembro de la Iglesia. Ya no se le define en categorías negativas (no son la jerarquía). Él mismo sostiene que la terminología utilizada ("laico", del sustantivo "laós") debe ser tomada en serio: "[...] laicos son los miembros del pueblo de Dios, condición de la que, de todos modos participamos todos los cristianos" (1987, p. 58).

b. El aspecto ministerial en la teología del laicado: este se refiere a la participación de auténticos ministerios que se le pueden conceder a los laicos dado el sacerdocio común que poseen. Dichos ministerios no son "una pura condición ornamental o metafórica del laicado y principalmente de todo el Pueblo de Dios", [sino que parten] de la conciencia viva de que toda la Iglesia está enviada en misión por voluntad del Señor, bajo la presidencia de la 'Jerarquía” (1987, p. 62). Se une así de forma inseparable jerarquía y laicado desde el concepto de pueblo, donde ninguno tiene más valor que el otro, sino que ambos son necesarios para la edificación de la comunidad.

Finalmente, el elemento testimonial vuelve también a aparecer en este tema cuando hace memoria de su ya citado maestro Mons. G. Philips y de Mons. Ch. Moeller, ambos decisivos en el devenir del Concilio y 
principalmente con relación a la Lumen Gentium. Sus palabras sirven de conclusión de este apartado sobre el testimonio y la teología de su eclesiología. Hoy, se puede también, y con justa razón, aplicarlas a él:

Yo quería precisamente hacer resonar el eco de la voz viva de estos inolvidables maestros, que me enseñaron a pensar teológicamente, que tanto hicieron por redescubrir el mejor rostro evangélico de la Iglesia, que tanto entusiasmo sintieron por el surgimiento que se anunciaba de una conciencia viva eclesial del laicado (1987, p. 64).

\section{Sacramentología}

Otro de los temas recurrentes en los escritos del padre Alberto es el de los sacramentos, de manera particular el de la Eucaristía, en los que, siguiendo la doctrina del Concilio Vaticano II, ve la actualización del misterio de la Pascua del Señor. Esta RSL se detendrá en tres aspectos relevantes en este sentido.

\section{El misterio de la Pascua del Señor.}

Una de los temas frecuentes en la teología del padre Alberto es el tema de la Pascua, que en su visión constituye no sólo el núcleo de la teología sacramental, sino la fuente de toda la cristología neotestamentaria. Se parte de un presupuesto: el padre Alberto afirma que "[...] el misterio salvador de Cristo no se reduce al misterio Pascual, sino que fue toda su existencia, relización del Reino de Dios; pero la culminación de ese acontecimiento fue la muerte gloriosa de Jesucristo" (1978, p. 45).

Ahora bien, haciendo referencia en concreto a su muerte, esta puede ser entendida como un sacrificio, pero no en el sentido de una ofrenda material sino en el de la ofrenda personal, de la ofrenda de la vida (1975, p. 47), teniendo presente que: "En la mentalidad bíblica la noción de sacrificio puede extenderse tanto a las ofrendas materiales, como a la ofrenda personal del que se ofrece. Aún más, esta última idea parece ser la razón profunda de todo sacrificio, porque aún en el caso de las ofrendas propiamente dichas, lo que en ellas se ofrece la persona del que sacrifica" (1975, p. 45).

Se muestra aquí una concepción particularmente interesante del misterio de la cruz: en ella Jesucristo no sólo ofrecía la ofrenda material 
de su cuerpo, sino que sobre todo se ofrecía a sí mismo; y esta es quizás la dimensión más importante del sacrificio pascual, y es lo que hace que a su vez se transforme en sacramento: sin la ofrenda de sí mismo, modelo de toda ofrenda, en tanto reveladora del amor de donación de Dios, la ofrenda de su cuerpo hubiera sido una ofrenda más al estilo de las de la antigua alianza; pero porque se ofrece a sí mismo, entonces se convierte en sacrificio salvador.

Es así como el sacrificio Pascual de Cristo abre a una dimensión nueva en la relación con Dios, donde se adentra la humanidad en la primacía de la gracia, manifestada en la ofrenda que Cristo hace de sí mismo; lo que hace que Él sea, en palabras de Melitón de Sardes, la Pascua de nuestra salvación.

\section{Los Sacramentos, actualización de la Pascua de Jesucristo.}

Teniendo como referente lo dicho sobre el misterio pascual de Jesucristo, el padre Alberto define los sacramentos como la obra salvífica del Seńor: "[...] su muerte redentora, que es cultualizada o transformada en materia cultual del sacrificio que ofrece el mismo Cristo como sacerdote" (1978, p. 51). A partir de esta expresión se desprenden varias consecuencias, a manera de principios, para comprender la vida sacramental de la Iglesia:

a. El punto de partida de toda la economía sacramental es que Cristo mismo es el sacramento fontal. En este sentido se ha de afirmar que todos los sacramentos deben ser referidos a Jesucristo, en la totalidad de su misterio original; de lo contrario, los sacramentos son puras acciones humanas y sus efectos salvíficos son engañosos (1983, p. 24).

b. Los sacramentos tienen eficacia salvífica "ex opere operato", afirmación que debe ser entendida por medio de la noción de actualización o presencialización, según la terminología de O. Casel; y que a su vez "se corresponde al sentido de "memorial" de los judíos, que estuvo de hecho presente en la mente del Señor, por ejemplo en el caso de la institución de la Eucaristía" (1983, p. 24).

c. Para que tal eficacia no sea un mero formalismo, el padre Alberto hace caer en cuenta de que es necesario insistir en la teología sacramental actual en la importancia decisiva de la actitud de fe, que debe suponerse en quien participa en el sacramento (1983, p. 24). En este sentido se ha de afirmar que si bien la fe es una actitud eclesial en la que la gracia actúa "ex opere operato", también involucra una dimensión personal que tiene que existir para acoger ese don de la gracia en la vida personal. 
d. Finalmente, habría que agregar que de la teología sacramental se desprenden unos presupuestos eclesiológicos fundamentales: "[...] el culto de la Iglesia, representado de manera particular en los sacramentos, no es más que la celebración de la continua actualidad de la obra salvífica realizada por el Señor, y en ellos la Iglesia misma se manifiesta visiblemente como comunidad de salvación" (1977, p. 63).

Sin embargo, esto no debe entenderse nunca en el sentido de un exclusivismo, pues si bien la Iglesia administra la gracia sacramental, no es poseedora de ella, ni la limita en sus propias fronteras, sino que ella actúa allende la Iglesia; en este sentido se explica muy bien el cambio del "extra ecclesiam nulla salus" por el "sine ecclesiam nulla salus" que manifiesta mucho mejor el que la Iglesia, nacida de la Pascua del Señor y que actualiza en los sacramentos la acción salvífica de Jesucristo, es ella misma "sacramento universal de salvación".

\section{El Sacramento de la Eucaristía}

Para el padre Alberto la actualización cultual de la obra salvífica de Cristo ha llegado a ser la ofrenda de la Iglesia, que de manera particular se manifiesta en la Eucaristía, "[...] pues ella hace posible la verdadera acción de gracias, en cuanto el verdadero don sacrificial que se puede ofrecer a Dios, es la persona (y obra salvífica) de Cristo" (1978, p. 55).

Dos afirmaciones fundamentales resumen toda la doctrina eucarística de la Iglesia:

a. La Eucaristía es el sacramento de la obra salvífica del Señor, en último término de su persona; y es en este sentido en que se puede decir que la Eucaristía es el signo eficaz (sacramento) de la presencia real del Señor.

b. La Eucaristía es un sacrificio. Pero aquí se debe hacer de nuevo una distinción:

i. La Eucaristía es el sacramento del sacrificio de Cristo, es decir, el signo eficaz de su obra salvífica total.

ii. La Eucaristía es el sacrificio de la Iglesia, la verdadera ofrenda sacrificial que la Iglesia posee como culto (1978, p. 43). 
La relación entre estas dos últimas variantes parece capital en la teología eucarística del padre Alberto, tanto así que llega a afirmar que: "la Eucaristía no puede dejar de ser el sacrificio personal de Cristo actualizado en la celebración, so pena de cosificar lamentablemente los dones eucarísticos. Ofrenda cultual sí, pero que supone la ofrenda personal de Cristo presente, su sacrificio martirológico" (1978, p. 55).

Frente a la estructura celebrativa de la Eucaristía, el padre Alberto afirma que cada una de las dos grandes partes que comprenden la Eucaristía - liturgia de la Palabra y Liturgia de la Eucaristía -, "realiza, a su manera, la totalidad del diálogo sacramental entre Dios y el hombre en Jesucristo" (1983, p. 38).

En la liturgia de la Palabra, se obra un diálogo, realizado por medio del signo de comunicación que se llama "la palabra":

La palabra del hombre consiste en himnos pronunciados por la comunidad, o en respuestas a las lecturas bíblicas. La Palabra de Dios son propiamente las lecturas de la Escritura. Y así se realiza el diálogo sacramental de la salvación: Dios le habla al hombre, y el hombre responde a Dios, con una palabra de fe, de acogida y en comunidad (1983, p. 39).

En la liturgia Eucarística, la Iglesia hace el memorial de la muerte del Señor, tal y como Él lo anticipó en el velo de los signos del pan y el vino, y así verdaderamente, según la afirmación de San Pablo: "cada vez que comemos de este pan y bebemos de este cáliz, anunciamos la muerte del Señor" (1 Cor 11,26), y al hacerlo, se comprende que el pan y el vino son signos de la salvación realizada por Jesucristo en el misterio de la cruz.

Una importancia particular tiene para el padre Alberto el signo de la comunión, donde se funden varias dimensiones: en primer lugar, la comunión expresa sacramentalmente que se vive en Él y que el proyecto cristiano es vivir la vida en Él; pero también es un misterio de comunión fraternal: el cristiano se une profundamente con los otros y así se constituye la Iglesia (1983, p. 39). Se puede decir, en definitiva, que en la Eucaristía se hace realidad sacramental y simbólicamente lo que acontece en la vida: "la salvación que acontece por la fe en Él, y que en el misterio Eucarístico se hace realidad sacramental" (1983, p. 37). 


\section{CONCLUSIONES}

En esta RSL, al revisar los temas recurrentes, se pudo intuir que el padre Alberto Ramírez tiene una línea de pensamiento teológico propia que, partiendo de las fuentes magisteriales y mirando la realidad en su totalidad, trata de:

a. Responder al hombre en todas sus dimensiones, no sólo desde los deseos de su razón, sino también de los del corazón.

b. Ser una teología abierta a una visión de futuro, con un horizonte de esperanza, pues como solía decir continuamente en sus clases: "Dios siempre va un paso adelante del hombre".

c. Ser una teología profundamente eclesial y eclesiológica, puesto que reconoce que el sujeto de la teología es la Iglesia, que en su devenir histórico reconoce la acción salvífica de un Dios que se deja pensar y sońar; y, por otro lado, es una teología que piensa y sueña una Iglesia que responda a los desafíos del hombre y del mundo para ser sacramento universal de salvación.

Finalmente, esta RSL sobre el legado teológico del padre Alberto abre un horizonte para comprender que toda su obra merece ser más explorada por los teólogos profesionales para descubrir en ella una fuente del pensamiento teológico latinoamericano.

\section{LISTA DE REFERENCIAS}

Ramírez, A. (1974a). El problema de la historia a la luz de la teología. Cuestiones teológicas 1(1), 75-81.

(1974b). Escritura - Teología - Iglesia. Cuestiones teológicas 1(1), 82-95.

(1975a). La pascua del Señor. Cuestiones teológicas 2(3), 3-60.

(1975b). Síntesis sistemática sobre la propia identidad de los ministerios y carismas en la Iglesia 2(5), 2-28

(1976). La revelación de Dios y su transmisión. Cuestiones teológicas 3(6), 15-34. 
(1977). Eucaristía y sacerdocio 4(1), 62-77.

(1978a). La Iglesia como comunidad ministerial . Reflexiones teológicodogmáticas acerca de la comunidad eclesial como contexto de los ministerios. Cuestiones Teológicas 5 (11), 38-51.

(1978b). La Eucaristía sacramento sacrificial de la Iglesia. Cuestiones teológicas 5(12), 43-55.

(1983a). Fundamentos doctrinales para una teología sobre la acción del laico. Cuestiones Teológicas 10 (26), 24-35. 23-56.

(1983b). Apuntes sobre los sacramentos. Cuestiones Teológicas 10 (27),

(1985). A los 20 años de la clausura del concilio ecuménico vaticano II. Cuestiones Teológicas 12 (34), 100-106

(1986a). Qué es hacer teología. Cuestiones teológicas 13(35), 73-80.

(1986b). La experiencia de Dios. Cuestiones teológicas 13(36), 61-78.

(1987). La dimensión hermenéutica de la fe y el proyecto hermenéutico en teología. Cuestiones teológicas 14(39), 39-45.

(1987). La teología del laicado desde el concilio Vaticano II hasta el sínodo mundial actual. Cuestiones Teológicas 14 (39), 49-64

(1998). "Medellín” y el origen reciente de la vocación profética de nuestra Iglesia en América Latina. Cuestiones Teológicas 24 (63), 21-44.

(1999). El reto actual de la apertura toca también a la Iglesia y a la teología: Consideraciones en torno al futuro de la vocación profética de la Iglesia y de la teología en América Latina. Cuestiones Teológicas 26 (66), 123-144.

(2000). Consideraciones teológicas acerca del misterio de Dios. Cuestiones teológicas 27(67), 81-115.

(2003) . A los 40 años de la inauguración del Concilio Vaticano II. Cuestiones Teológicas 30 (73), 29-55

(2012). La palabra y el silencio. Categorías antropológicas para desentrañar el fenómeno de la revelación y de la fe. Cuestiones teológicas 39 (92), 197-214. 